\title{
Effects of Leukotriene Receptor Antagonists on Peripheral Eosinophil Counts and Serum IgE Levels in Children with Food Allergy
}

Yoko Yamakawa, ${ }_{1}$ Yoshikazu Ohtsuka, ${ }_{1}$ Kiyotaka Ohtani ${ }^{1}$ Tohru Fujii, ${ }^{1}$ Satoru Nagata, ${ }^{2}$ Yuichiro Yamashiro ${ }^{2}$ and Toshiaki Shimizu ${ }^{1}$

1 Department of Pediatrics and Adolescent Medicine, Juntendo University School of Medicine, Tokyo, Japan

2 Division of Probiotics Research, Juntendo University School of Medicine, Tokyo, Japan

\section{Abstract}

Background: Although the efficacy of leukotriene receptor antagonists (LTRAs) for bronchial asthma is already established, their effect on food allergy remains unclear.

Objective: To investigate the efficacy of LTRAs in children with food allergy. Methods: This retrospective study examined 65 children with food allergy who

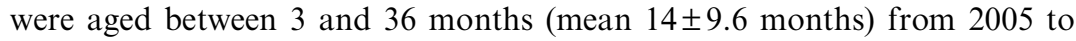
2008. Thirty-two children were treated as a dietary control group by avoiding any antigenic foods to which they had previously experienced adverse reactions. The remaining 33 children, designated the LTRA group, were treated with pranlukast ( $7 \mathrm{mg} / \mathrm{kg}$ bodyweight/day) in addition to maintaining dietary control. Clinical symptoms and laboratory data before and after 1 year of treatment were compared between the groups.

Results: Allergic symptoms improved in both the dietary controlled and LTRA groups, and there was no significant difference observed in the clinical parameters examined between the groups after the 1-year trial. Peripheral eosinophil count, serum IgE, interleukin (IL)-4, IL-5, IL-6, and eosinophil cationic protein (ECP) levels in children with food allergy were above standardized values in both groups. Although both the dietary controlled and LTRA groups showed a decreased eosinophil count $(-273 \pm 232$ vs $-595 \pm 295 / \mu \mathrm{L} ; \mathrm{p}<0.05$ and $\mathrm{p}<0.001$, respectively), only children treated with LTRA showed a significant decrease in serum IgE $(-73.5 \pm 115 \mathrm{IU} / \mathrm{mL} ; \mathrm{p}<0.01)$; conversely, the control group exhibited a significant increase in serum $\operatorname{IgE}(+159 \pm 138 \mathrm{IU} / \mathrm{mL} ; \mathrm{p}<0.01)$. Furthermore, the LTRA group also showed a significant decrease in serum IL-4 (54.5 \pm 31.0 to $27.3 \pm 10.1 \mathrm{pg} / \mathrm{mL}), \mathrm{IL}-5(6.7 \pm 5.2$ to $5.0 \pm 0.4 \mathrm{pg} / \mathrm{mL})$, and ECP $(45.4 \pm 15.0$ to $15.0 \pm 9.8 \mu \mathrm{g} / \mathrm{L})$ levels $(\mathrm{p}<0.05$ for each). 
Conclusion: Early intervention with LTRAs may be effective in regulating eosinophil count and serum IgE, IL-4, IL-5, and ECP levels. These data support the potential effectiveness of LTRAs in young children with food allergy to prevent further allergic development.

\section{Introduction}

Food allergy is defined as an adverse response initiated by the immune system to a specific food antigen. ${ }^{[1-3]}$ These adverse responses, including anaphylactic shock, can arise in many tissues of the body, including the skin, conjunctiva, and gastrointestinal and respiratory tracts. In general, food allergy occurs more commonly in younger children, including infants. ${ }^{[2,4]}$ After the age of 3 years, more than $70 \%$ of these children are expected to be free from allergic symptoms related to ingested foods, known as 'tolerance'. ${ }^{[4-9]}$ After this time, they tend to develop further allergic diseases, including asthma, allergic rhinitis, and conjunctivitis with increased levels of serum $\mathrm{IgE}$. This sequential development of allergic disease manifestations is often referred to as the 'atopic march'. It is considered that early intervention in children with food allergy is important to prevent development of the atopic march. ${ }^{[10]}$

The most fundamental management of children with food allergy in the acute phase is to prevent them from ingesting any antigenic foods and to provide foods in which antigens are deconstructed, such as hydrolyzed formula in patients with milk allergy. ${ }^{[11]}$ When anaphylactic reactions occur, exposure may be fatal for these children; therefore, medical management that can reduce or treat allergic symptoms arising from antigen ingestion must be developed.

Cysteinyl leukotrienes (Cys-LTs) are potent pro-inflammatory mediators derived from arachidonic acid through the 5-lypoxigenase pathway. By competitive binding to the Cys-LT receptor, a leukotriene receptor antagonist (LTRA) [e.g. montelukast or pranlukast] blocks the effects of Cys-LTs and alleviates the symptoms of many chronic allergic diseases, including bronchial asthma. ${ }^{[12]}$ The clinical effect of montelukast for pediatric asthma was first reported in $1998{ }^{\left[{ }^{[13]}\right.}$ It has been used since that time, and its effectiveness is recognized worldwide. ${ }^{[14]}$ Meanwhile, the effectiveness of pranlukast, a novel LTRA developed in Japan, for the treatment of asthma is also confirmed in the Western world. A double-blind, placebo-controlled, multicenter clinical study of pranlukast in mild to moderate asthma was performed in the US and Europe, and its safety and tolerability were also established. ${ }^{[15,16]}$ In Japan, montelukast and pranlukast are used for the treatment of asthma, and their effectiveness against asthma is equally accepted. ${ }^{[17]}$

In this study, we investigated the efficacy of LTRA in children with food allergy as an early intervention, in terms of clinical outcome, eosinophil counts, and pro-inflammatory cytokine levels.

\section{Methods}

\section{Participants and Studies}

All study protocols were approved by the Institutional Ethics Committee of Juntendo University Hospital, and informed consent for participation was obtained from the parents of all children prior to enrollment in the study.

This is a retrospective review of 65 children with food allergy between the ages of 3 and 36 months (mean $14 \pm 9.6$ months) who underwent dietary control with or without LTRA treatment (table I). All patients were monitored at the Juntendo University Hospital between the years of 2005 and 2008 under the diagnosis of food allergy. No cases of parasitosis were confirmed among these patients. The diagnosis of food allergy was established by open food challenge test and by confirmed adverse responses, such as diarrhea, vomiting, occult bloody stool, rash, eczema, coughing, and wheezing, after antigenic food ingestion under the physician's supervision. A total of 32 children were treated with dietary 
Table I. Characteristics of the population studied

\begin{tabular}{llll}
\hline Parameter & Normal range & \multicolumn{2}{l}{ Children with food allergy $(\mathrm{n}=65)^{\mathrm{a}}$} \\
\cline { 3 - 4 } & & dietary controlled group $(\mathrm{n}=32)$ & LTRA group $(\mathrm{n}=33)$ \\
\hline Age (years) & & $1.2 \pm 0.8$ & $1.3 \pm 0.8$ \\
Male/female $(\mathrm{n})$ & $20 / 12$ & $24 / 9$ \\
Eosinophil $(/ \mu \mathrm{L})$ & $<450$ & $950 \pm 564$ & $981 \pm 537$ \\
$\mathrm{IgE}(\mathrm{IU} / \mathrm{mL})$ & $<170$ & $607 \pm 585$ & $612 \pm 593$ \\
ECP $(\mu \mathrm{g} / \mathrm{L})$ & $<14.7$ & $35.0 \pm 13.0$ & $45.4 \pm 15.0$ \\
$\mathrm{IL}-4(\mathrm{pg} / \mathrm{mL})$ & $<13.9$ & $49.9 \pm 29.4$ & $54.5 \pm 31.0$ \\
$\mathrm{IL}-5(\mathrm{pg} / \mathrm{mL})$ & $<5$ & $6.0 \pm 2.6$ & $6.7 \pm 5.2$ \\
$\mathrm{IL}-6(\mathrm{pg} / \mathrm{mL})$ & $<0.7$ & $2.3 \pm 2.2$ & $2.2 \pm 3.0$ \\
TGF- $\beta 1(\mathrm{ng} / \mathrm{mL})$ & $<11$ & $40.6 \pm 14.7$ & $44.9 \pm 11.7$ \\
\hline
\end{tabular}

a Values are expressed as mean \pm SD. Mann-Whitney U-tests were performed, and no significant differences were found in age, eosinophil counts, serum IgE, ECP, IL-4, IL-5, IL-6, or TGF- $\beta 1$ levels between the groups. $2 \times 2$ chi-squared tests were performed, and no significant differences were found in sex distribution between the groups.

$\mathbf{E C P}=$ eosinophil cationic protein; IL = interleukin; $\mathbf{L T R A}=$ leukotriene receptor antagonist; TGF = transforming growth factor .

control only and assigned to the dietary controlled group. The remaining 33 children were treated with LTRA in addition to the dietary control for 1 year and assigned to the LTRA group. Dietary control was performed according to the Japanese pediatric guideline for food allergy 2005. ${ }^{[18]}$ Dietary control was applied through avoidance of foods that had triggered the previously confirmed adverse reactions. Routine clinical examination, with confirmation of LTRA administration from the parents in the LTRA group, was performed every month during this study. During the study period, food challenge tests were conducted periodically to determine if tolerance to specifically identified antigenic foods had developed. Once tolerance had been established, children were allowed to ingest antigenic foods in small amounts.

Pranlukast ( $7 \mathrm{mg} / \mathrm{kg}$ bodyweight/day) was administered orally to the children in the LTRA group. All children were allowed to use any drugs including corticosteroid ointment, but any oral administration of corticosteroids was temporarily ceased. In addition, all children in the dietary controlled group did not use any LTRAs during this study. Before and at the end of the 1-year trial, we performed statistical comparisons of clinical symptoms and the laboratory data, including peripheral eosinophil count, and levels of serum IgE, cytokines related to allergic reactions (interleukin [IL]-4, $-5,-6$, transforming growth factor [TGF]- $\beta 1$ ), and eosinophil cationic protein (ECP). Clinical symp- toms were evaluated as positive with confirmation of occult bloody stool, diarrhea, vomiting, eczema, rash, wheezing, failure to thrive, and anaphylaxis after intake of food antigens at the time of physician observation (table II).

\section{Determination of Serum Cytokine and Eosinophil Cationic Protein Levels by ELISA}

To determine serum cytokine and ECP levels in children with food allergy, ELISA kits for human IL-4 (R\&D Systems Europe, Oxon, UK), IL-5 (R\&D Systems Europe), IL-6 (Fujirebio,

Table II. Clinical symptoms before and after the trial ${ }^{\mathrm{a}}$

\begin{tabular}{|c|c|c|c|c|}
\hline \multirow[t]{2}{*}{ Symptom } & \multicolumn{2}{|c|}{$\begin{array}{l}\text { Dietary controlled group } \\
(\mathrm{n}=32)\end{array}$} & \multicolumn{2}{|l|}{$\begin{array}{l}\text { LTRA group } \\
(n=33)\end{array}$} \\
\hline & before trial & $\begin{array}{l}\text { after } \\
1 \text { year }\end{array}$ & before trial & $\begin{array}{l}\text { after } \\
1 \text { year }\end{array}$ \\
\hline Bloody stool & 6 & 0 & 5 & 0 \\
\hline Diarrhea & 5 & 0 & 4 & 0 \\
\hline Vomiting & 3 & 0 & 2 & 0 \\
\hline Failure to thrive & 4 & 1 & 7 & 0 \\
\hline Eczema & 13 & 3 & 16 & 4 \\
\hline Rash & 5 & 1 & 6 & 1 \\
\hline Wheezing & 4 & 1 & 4 & 1 \\
\hline Anaphylaxis & 1 & 0 & 0 & 0 \\
\hline
\end{tabular}

a Both the dietary controlled and LTRA groups showed reduced allergic symptoms after the trial. $2 \times 2$ chi-squared and Fisher's tests were performed, and no significant differences were found in reduced allergic symptoms between the groups.

LTRA = leukotriene receptor antagonist. 
Tokyo, Japan), TGF- $\beta 1$ (R\&D Systems Europe), and ECP (Roche Diagnostic, Basel, Switzerland) were used according to the manufacturers' instructions. Each ELISA assay was performed in triplicate.

\section{Statistical Analysis}

Because the majority of the data were not normally distributed, we used nonparametric analysis. Data were analyzed using Wilcoxon $t$-tests when each value was compared before and after the trial. The Mann-Whitney U-test, $2 \times 2$ chisquared test, and Fisher's exact test were used to determine significant differences between the groups. Values of $\mathrm{p}<0.05$ were considered statistically significant.

\section{Results}

\section{Participant Characteristics}

At baseline, peripheral eosinophil count and serum IgE, IL-4, IL-5, IL-6, and ECP levels in children with food allergy were above the standard levels obtained from healthy children in our facility (table I). Furthermore, there were no significant differences in clinical symptoms, age, peripheral eosinophil count, and serum $\operatorname{IgE}$ and cytokine levels between the dietary controlled and LTRA groups before the trial (tables I-III).

Allergic symptoms following intake of a specific food antigen in these patients at baseline included gastrointestinal symptoms, such as bloody stool (11 cases, 17\%), diarrhea ( 9 cases, 14\%), vomiting (5 cases, $8 \%$ ), and failure to thrive (11 cases, 17\%); skin responses, such as eczema (29 cases, $45 \%$ ) and rash (11 cases, 17\%); and respiratory symptoms, such as wheezing ( 8 cases, 12\%) [table II]. Weanling infants showed more symptoms that overlapped with gastrointestinal tract symptoms. There was one child in the dietary controlled group who experienced an anaphylactic reaction after antigen ingestion. There were nine children who had food allergy in combination with asthma, 29 with atopic dermatitis, and none with allergic rhinitis.

Antigen-specific IgE antibodies were frequently detected at baseline against egg white (30 cases,
Table III. Antigen-specific IgE antibodies before and after the trial ${ }^{\mathrm{a}}$

\begin{tabular}{llllll}
\hline Antigen & \multicolumn{2}{l}{$\begin{array}{l}\text { Dietary controlled group } \\
(\mathrm{n}=32)\end{array}$} & & \multicolumn{2}{l}{$\begin{array}{l}\text { LTRA group } \\
(\mathrm{n}=33)\end{array}$} \\
\cline { 2 - 3 } \cline { 5 - 6 } & before trial & after 1 year & before trial & after 1 year \\
\hline Egg white & 13 & 9 & 17 & 10 \\
Ovomucoid & 4 & 3 & 6 & 4 \\
Cow's milk & 8 & 4 & 10 & 6 \\
Wheat & 5 & 4 & 6 & 4 \\
Soybean & 4 & 2 & 7 & 2 \\
\hline
\end{tabular}

a Both the dietary controlled and LTRA groups showed decreased specific IgE after the trial. $2 \times 2$ chi-squared and Fisher's tests were performed, and no significant differences were found in antigen-specific $\lg E$ levels between the groups.

LTRA = leukotriene receptor antagonist.

$46 \%$ ), cow's milk (18 cases, $28 \%$ ), wheat (11 cases, $17 \%$ ), and soybean (11 cases, 17\%) among all of the patients. There were no significant differences in antigen specificity between the dietary controlled and LTRA groups in this study (table III).

\section{Effects of LTRA}

No patients experienced any adverse reactions after the LTRA administration during this study. The number of patients who showed specific allergic symptoms after food ingestion was decreased after 1 year in both the dietary controlled and LTRA groups (table II). There were 13 children $(40.6 \%)$ in the dietary controlled group and 15 children $(45.5 \%)$ in the LTRA group who established tolerance, confirmed by a food challenge test, to antigenic foods that were identified at the beginning of this trial. However, there was no significant difference between the dietary controlled and LTRA group for these factors.

The peripheral eosinophil count was significantly decreased in both the dietary controlled $(\mathrm{p}<0.05)$ and LTRA groups $(\mathrm{p}<0.001)$ after the trial (figure 1). However, the decrease in peripheral eosinophil counts was significantly greater in the LTRA group (mean $\pm \mathrm{SD}$, control $-273 \pm 232 / \mu \mathrm{L}$; LTRA $-595 \pm 295 / \mu \mathrm{L}, \mathrm{p}<0.05$ ) [figure $2 \mathrm{a}$ ].

Serum $\operatorname{IgE}$ levels in the dietary controlled group significantly increased $(\mathrm{p}<0.01)$ despite reduced symptoms after the trial, whereas levels in the LTRA group had significantly decreased after the treatment $(\mathrm{p}<0.01)$ [figure 1]. There was a significant difference in the change in serum IgE lev- 

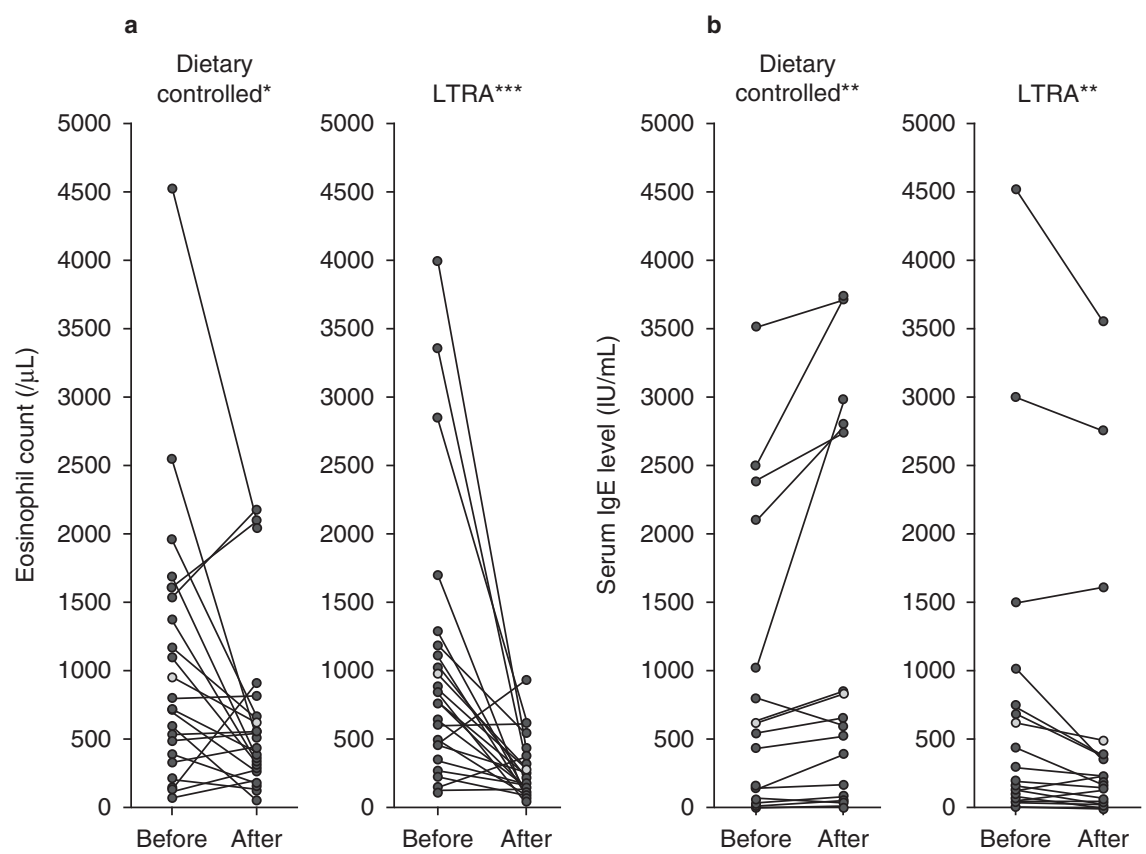

Fig. 1. (a) Peripheral eosinophil counts and (b) serum IgE levels before and after the trial in the dietary controlled and leukotriene receptor antagonist (LTRA) groups. The peripheral eosinophil count was significantly decreased after 1 year in the dietary controlled and LTRA groups. The serum IgE level of the dietary controlled group was significantly increased, whereas that of the LTRA group was significantly decreased after treatment. Data were analyzed using Wilcoxon $t$-tests. ${ }^{*} p<0.05,{ }^{* *} p<0.01,{ }^{* * *} p<0.001$.

els between the LTRA group $(-73.5 \pm 115 \mathrm{IU} / \mathrm{mL})$ and the dietary controlled group $(+159 \pm 138 \mathrm{IU} / \mathrm{mL})$ $[\mathrm{p}<0.01$; figure $2 \mathrm{~b}]$. Serum antigen-specific IgE levels decreased in both groups, and there was no sig- nificant difference confirmed between the groups in each level (table III). Furthermore, there were significant decreases in serum ECP (from $45.4 \pm 15.0$ to $15.0 \pm 9.8 \mu \mathrm{g} / \mathrm{L}$ ), IL-4 (from $54.5 \pm 31.0$ to
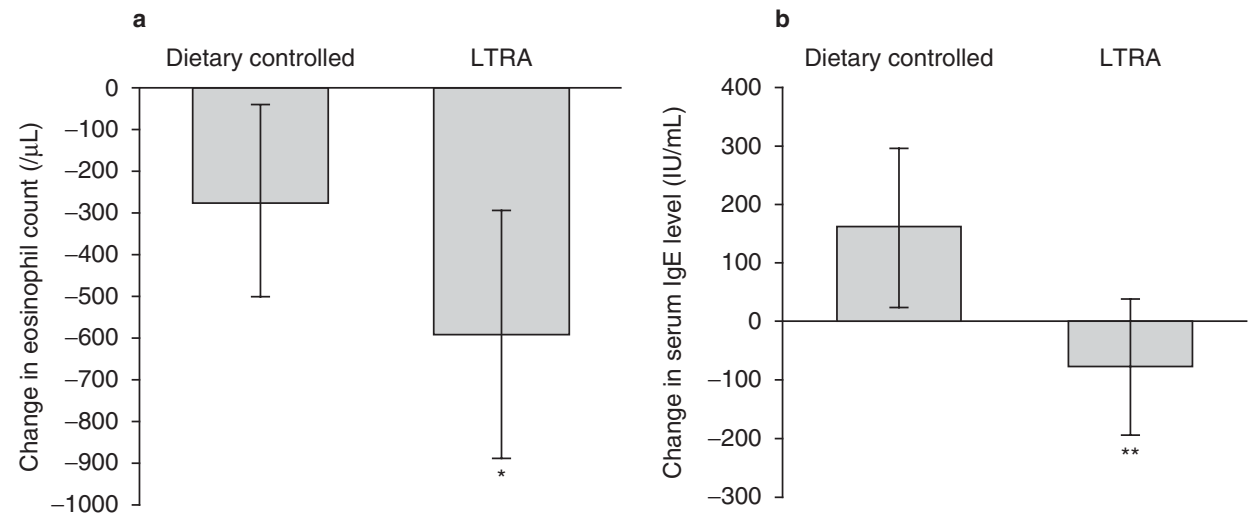

Fig. 2. Change in (a) peripheral eosinophil counts and (b) serum IgE levels during the trial in the dietary controlled and leukotriene receptor antagonist (LTRA) groups. The decrease in peripheral eosinophil counts was significantly greater in the LTRA group when compared with that in the dietary controlled group. The decrease in serum IgE levels in the LTRA group was significantly different from the increase in the dietary controlled group. Data were analyzed using the Mann-Whitney U-test. ${ }^{*} p<0.05,{ }^{* *} p<0.01$. 


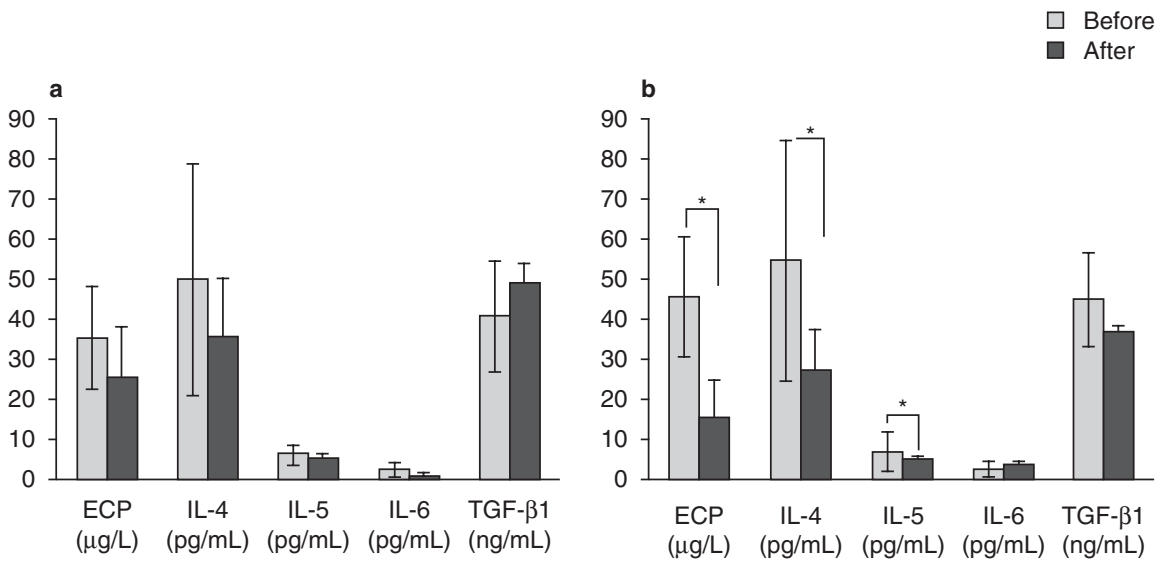

Fig. 3. Serum eosinophil cationic protein (ECP) and pro-inflammatory cytokine levels before and after the trial in the (a) dietary controlled and (b) leukotriene receptor antagonist (LTRA) groups. The serum ECP, interleukin (IL)-4, and IL-5 levels in the LTRA group were significantly decreased after the LTRA treatment. Data were analyzed using Wilcoxon $t$-tests. Results are means $\pm S D$. TGF =transforming growth factor; * $\mathrm{p}<0.05$.

$27.3 \pm 10.1 \mathrm{pg} / \mathrm{mL}$ ), and IL-5 (from $6.7 \pm 5.2$ to $5.0 \pm 0.4 \mathrm{pg} / \mathrm{mL}$ ) levels after treatment with LTRA $(\mathrm{p}<0.05$ for each), but there was no significant change in ECP (from $35.0 \pm 13.0$ to $25.4 \pm 12.8 \mu \mathrm{g} / \mathrm{L}$ ), IL-4 (from $49.9 \pm 29.4$ to $35.3 \pm 15.1 \mathrm{pg} / \mathrm{mL}$ ), or IL-5 (from $6.0 \pm 2.6$ to $5.3 \pm 1.0 \mathrm{pg} / \mathrm{mL}$ ) in the dietary controlled group after 1 year (figure 3 ).

\section{Discussion}

The present study demonstrates the effectiveness of LTRA treatment in children with food allergy by showing a significant decrease in peripheral eosinophil count and serum IgE, IL-4, IL-5, and ECP levels. Since IL-4 stimulates IgE synthesis and IL-5 promotes eosinophil migration leading to enhanced allergic reactions, LTRA treatment may protect young children with food allergy from further allergic development. Although the clinical benefit was not confirmed after 1 year of LTRA administration in this study, it may be possible to confirm its clinical benefits with longer duration.

Eosinophils and mast cells produce Cys-LT, which has several effects on local tissues, including eosinophil activation and migration. LTRA, which inhibits Cys-LTs, is also reported to suppress the production of Cys-LTs (e.g. leukotriene C4 [LTC4] and leukotriene D4), cytokines (e.g.
IL-4 and IL-5), and the expression of nuclear factor- $\kappa \mathrm{B}(\mathrm{NF}-\kappa \mathrm{B})$, as well as eosinophil activation, leading to reduced eosinophilic migration into local tissue. ${ }^{[19-23]}$ The Cys-LT1 receptor antagonists montelukast and pranlukast are well known to have clinical benefits for the treatment and management of allergic diseases, particularly asthma. Several studies have suggested that pranlukast inhibits lipopolysaccharide-induced IL-6, allergen-specific tumor necrosis factor- $\alpha$ $(\mathrm{TNF} \alpha)$ and $\mathrm{T}$ helper-2 $\left(\mathrm{T}_{\mathrm{h}} 2\right)$-type cytokine production and the translocation of NF- $\mathrm{BB}$, a ubiquitous transcription factor for genes that encode pro-inflammatory cytokines such as IL-1, IL-6, IL-8, and TNF $\alpha \cdot{ }^{[24-26]}$ Clinical allergic symptoms as well as eosinophil count, serum IgE, and IL-4 levels have been shown to drop significantly after LTRA treatment in children with allergic rhinitis and Kimura's disease. ${ }^{[27-29]}$ The effectiveness of LTRAs was also reported in allergic eosinophilic esophagitis, a rarely diagnosed condition involving eosinophil infiltration of the esophageal mucosa among infants. ${ }^{[30]}$

Serum IgE levels were significantly increased in the control group as a natural course of illness despite dietary treatment, but were significantly decreased in the LTRA group. These results suggest that early intervention with LTRA may protect children with food allergy from further 
IgE synthesis, possibly by regulating eosinophil migration and $\mathrm{T}_{\mathrm{h}}$ 2-type cytokine production. Ohshima et al. ${ }^{[22]}$ have reported that intracrine Cys-LT receptor-mediated signaling induced by LTC4 acts as an intracrine mediator of eosinophil IL-4 secretion. Our findings also suggest that LTRA is beneficial in the clinical management of children with food allergy by attenuating IL-4 and IL-5 production. As IL-4 and IL-5 are important cytokines in IgE synthesis and eosinophil migration, LTRA may reduce the present allergic symptoms as well as preventing further progression of allergic inflammation in children through this mechanism of action. Since the improvement of laboratory data is different from the preventive effect on the allergic diseases, further study is necessary to prove the potential effects of LTRAs in regulating the development of allergic diseases.

In this study, we focused on children with food allergy who were under 3 years of age and who were administered LTRA as an early intervention. These children have weaker intestinal function in terms of digestion and tight junction development, which results in a greater intestinal permeability than adults. ${ }^{[31]}$ In the presence of eosinophilia, eosinophil degranulation can further increase intestinal permeability and enhance transmigration of undigested peptides from the intestinal lumen to the systemic circulation, ${ }^{[32]}$ which may cause these children to develop allergic reactions more easily. Because young children often show eosinophilia, this condition can be a risk factor for them to develop future allergic diseases. Furthermore, since elevated levels of ECP were confirmed in children with food allergy, regulating eosinophil migration into the intestine and reducing the total amount of ECP secreted from eosinophils by LTRA treatment may possibly protect children with food allergy from further allergic progression.

\section{Conclusion}

Although the clinical benefit of pranlukast was not confirmed after this 1-year trial, these results suggest that early intervention with LTRA is effective in regulating eosinophil count and serum IgE, IL-4, IL-5, and ECP levels; with long-term use, LTRA may also be effective in preventing further allergic development, especially in young children with food allergy. Further study is necessary to confirm the potential use of LTRA in the prevention of allergic inflammation in children with food allergy.

\section{Acknowledgments}

This study was partially supported by grants from the Japan Society for the Promotion of Science, Japan. The authors have not conflicts of interest that a directly relevant to the content of this article.

\section{References}

1. Bruijnzeel-Koomen C, Ortolani C, Aas K, et al. Adverse reactions to food. European Academy of Allergology and Clinical Immunology Subcommittee. Allergy 1995; 50: 623-35

2. Sampson HA. Food allergy. J Allergy Clin Immunol 2003; 111: S540-7

3. Sampson HA. Food allergy. Part 1: immunopathogenesis and clinical disorders. J Allergy Clin Immunol 1999; 103: 717-28

4. Bock SA. Prospective appraisal of complaints of adverse reactions to foods in children during the first 3 years of life. Pediatrics 1987; 79: 683-8

5. Bishop JM, Hill DJ, Hosking CS. Natural history of cow milk allergy: clinical outcome. J Pediatr 1990; 116: 862-7

6. Eggleston PA. Prospective studies in the natural history of food allergy. Ann Allergy 1987; 59: 179-82

7. Guillet G, Guillet MH. Natural history of sensitizations in atopic dermatitis. A 3-year follow-up in 250 children: food allergy and high risk of respiratory symptoms. Arch Dermatol 1992; 128: 187-92

8. Hill DJ, Firer MA, Ball G, et al. Natural history of cow's milk allergy in children: immunological outcome over 2 years. Clin Exp Allergy 1993; 23: 124-31

9. Host A. Cow's milk protein allergy and intolerance in infancy: some clinical, epidemiological and immunological aspects. Pediatr Allergy Immunol 1994; 5: 1-36

10. MacDonald TT, Di Sabatino A. The immunologic basis for gastrointestinal food allergy. Curr Opin Gastroenterol 2009; 25: 521-6

11. Ohtsuka Y, Sanderson IR, MacDonald TT. Food intolerance: chapter 23. In: Preedy V, Grimble G, Watson R, editors. Nutrition in the infant: problems and practical procedures. London: Greenwich Medical Media Ltd, 2001: 247-56

12. Duroudier NP, Tulah AS, Sayers I. Leukotriene pathway genetics and pharmacogenetics in allergy. Allergy 2009; 64: 823-39

13. Knorr B, Matz J, Bernstein JA, et al. Montelukast for chronic asthma in 6- to 14-year old children. JAMA 1998; 15: $1181-6$

14. Global Initiative for Asthma (GINA) [online]. Available from URL: http://www.ginasthma.org [Accessed 2010 Sep 14]

15. Barnes NC, Pujet JC. Pranlukast, a novel leukotriene receptor antagonist: results of the first European, placebo 
controlled, multicenter clinical study in asthma. Thorax 1997; 52: 523-7

16. Grossman J, Faiferman I, Dubb JW, et al. Results of the first U.S. double-blind, placebo-controlled, multicenter clinical study in asthma with pranlukast, a novel leukotriene receptor antagonist. J Asthma 1997; 34: 321-8

17. Morikawa A, Nishima S, for the Japanese Society of Pediatric Allergy and Clinical Immunology. New Japanese pediatric guidelines for the treatment and management of bronchial asthma. Pediatr Int 2007; 49: 1023-31

18. Ebisawa M. Management of food allergy: food allergy management 2005 by National Food Allergy Research Group [in Japanese]. Arerugi 2006; 55: 107-14

19. Nagata M, Saito K, Kikuchi I, et al. Effect of the cysteinyl leukotriene antagonist pranlukast on transendothelial migration of eosinophils. Int Arch Allergy Immunol 2005; 137: 2-6

20. Fukushima C, Matsuse H, Hishikawa Y, et al. Pranlukast, a leukotriene receptor antagonist, inhibits interleukin-5 production via a mechanism distinct from leukotriene receptor antafonism. Int Arch Allergy Immunol 2005; 136: 165-72

21. Nakai H, Konno M, Kosuge S, et al. New potent antagonists of leukotrienes C4 and D4: synthesis and structureactivity relationships. J Med Chem 1998; 31: 84-91

22. Ohshima N, Nagase H, Koshino T, et al. A functional study on CysLT(1) receptors in human eosinophils. Int Arch Allergy Immunol 2002; 129: 67-75

23. Suzuki M, Kato M, Kimura H, et al. Inhibition of human eosinophil activation by a cysteinyl leukotriene receptor antagonist (pranlukast; ONO-1078). J Asthma 2003; 40: 395-404

24. Ichiyama T, Hasegawa $S$, Umeda $K$, et al. Pranlukast inhibits NF- $\mathrm{KB}$ activation in human monocytes/macrophages and T cells. Clin Exp Allergy 2003; 33: 802-7

25. Tohda Y, Nakahara H, Kubo H, et al. Effects of ONO-1078 (pranlukast) on cytokine production in peripheral blood mononuclear cells of patients with bronchial asthma. Clin Exp Allergy 1999; 29: 1532-6

26. Tomari S, Matsuse H, Machida I, et al. Pranlukast, a cysteinyl leukotriene receptor 1 antagonist, attenuates allergen specific tumor necrosis factor alpha production and nuclear factor kappa B nuclear translocation in peripheral blood monocytes from atopic asthmatics. Clin Exp Allergy 2003; 33: 795-801

27. Chen ST, Lu KH, Sun HL, et al. Randomized placebocontrolled trial comparing montelukast and cetirizine for treating perennial allergic rhinitis in children aged 2-6 yr. Pediatr Allergy Immunol 2006; 17: 49-54

28. Sasaki K, Okamoto Y, Yonekura S, et al. Cedar and cyress pollinosis and allergic rhinitis: quality of life effects of early intervention with leukotriene receptor antagonists. Int Arch Allergy Immunol 2009; 149: 350-8

29. Ohtsuka Y, Shimizu T, Fujii T, et al. Pranlukast regulates tumor growth by attenuating IL-4 production in Kimura's disease. Eur J Pediatr 2004; 163: 416-7

30. Attwood SE, Lewis CJ, Bronder CS, et al. Eosinophilic oesophagitis: a novel treatment using montelukast. Gut 2003; 52: $181-5$

31. Strolin Benedetti M, Whomsley R, Baltes EL. Differences in absorption, distribution, metabolism and excretion of xenobiotics between the paediatric and adult populations. Expert Opin Drug Metab Toxicol 2005; 1: 447-71

32. Song DJ, Cho JY, Miller M, et al. Anti-Siglec-F antibody inhibits oral egg allergen induced intestinal eosinophilic inflammation in a mouse model. Clin Immunol 2009; 131: 157-69

Correspondence: Associate Professor Yoshikazu Ohtsuka, Department of Pediatrics and Adolescent Medicine, Juntendo University School of Medicine, 2-1-1, Hongo, Bunkyo-ku, Tokyo 113-8421, Japan.

E-mail: yohtsuka@juntendo.ac.jp 